\title{
A dynamic method based on the specific substrate uptake rate to set up a feeding strategy for Pichia pastoris
}

\author{
Christian Dietzsch, Oliver Spadiut, Christoph Herwig ${ }^{*}$
}

\begin{abstract}
Background: Pichia pastoris is one of the most important host organisms for the recombinant production of proteins in industrial biotechnology. To date, strain specific parameters, which are needed to set up feeding profiles for fed batch cultivations, are determined by time-consuming continuous cultures or consecutive fed batch cultivations, operated at different parameter sets.

Results: Here, we developed a novel approach based on fast and easy to do batch cultivations with methanol pulses enabling a more rapid determination of the strain specific parameters specific substrate uptake rate $q_{s}$, specific productivity $\mathrm{q}_{\mathrm{p}}$ and the adaption time ( $\Delta$ time $_{\text {adapt }}$ ) of the culture to methanol. Based on $\mathrm{q}_{\mathrm{s}}$ an innovative feeding strategy to increase the productivity of a recombinant Pichia pastoris strain was developed. Higher specific substrate uptake rates resulted in increased specific productivity, which also showed a time dependent trajectory. A dynamic feeding strategy, where the setpoints for $q_{s}$ were increased stepwise until a $q_{s} \max$ of $2.0 \mathrm{mmol} \cdot \mathrm{g}^{-1} \cdot \mathrm{h}^{-1}$ resulted in the highest specific productivity of $11 \mathrm{U} \cdot \mathrm{g}^{-1} \cdot \mathrm{h}^{-1}$.

Conclusions: Our strategy describes a novel and fast approach to determine strain specific parameters of a recombinant Pichia pastoris strain to set up feeding profiles solely based on the specific substrate uptake rate. This approach is generic and will allow application to other products and other hosts.
\end{abstract}

\section{Background}

Recombinant protein expression with biological hosts is one of the most examined key processes in the pharmaceutical industry. Numerous products like organic acids, antibiotics, enzymes and amino acids are produced heterologously by recombinant microorganisms. The methylotrophic yeast Pichia pastoris is one of the most important host organisms for this purpose.

Several of the published fermentation strategies for $P$. pastoris to date are based on the Invitrogen protocol http://tools.invitrogen.com. This protocol suggests constant feeding profiles for fed batch cultivations, but does not aim to improve production efficiency regarding time and yield or substrate consumption. Based on this protocol, different process strategies were developed to optimize recombinant protein production with $P$. pastoris in the past few years. A commonly used feeding

\footnotetext{
* Correspondence: christoph.herwig@tuwien.ac.at

Vienna University of Technology, Institute of Chemical Engineering, Research Area Biochemical Engineering, Vienna, Austria
}

strategy describes a feed forward regime based on a constant specific growth rate $\mu$ [1-5]. This strategy results in an exponential feeding profile and does not require complex instrumentation, but $\mu$ is also not controlled, and since the cells capacity may change over time, the feeding profiles consider a large safety margin. Another feeding strategy is based on a controlled $\mu$ and requires laborious continuous culture investigations and an effective computer controlled operation, based on established growth models and a feedback algorithm requiring expensive online measurement sensors for methanol [2,6-8]. Employing these strategies, the outcome regarding specific productivity and specific growth rate was diverse; some studies showed that the maximal specific productivity did not relate to the maximal specific growth rate $[1,3,6,7]$, whereas another study showed a more or less growth associated productivity [9].

Due to these controversial findings, other parameters were analyzed for their possible correlation with the productivity in the past few years. Khatri and Hoffmann

\section{Biomed Central}


analyzed the specific substrate uptake rate $\left(\mathrm{q}_{\mathrm{s}}\right)$ and its association with the specific productivity $\left(\mathrm{q}_{\mathrm{p}}\right)$ in fedbatch cultivations of $P$. pastoris and showed that lower $\mathrm{q}_{\mathrm{s}}$ resulted in higher $\mathrm{q}_{\mathrm{p}}[10,11]$. In another study, Cunha et al. used a constant feeding rate of methanol during several fed-batch cultivations with different initial biomass contents to monitor $\mathrm{q}_{\mathrm{s}}$ over time [12]. Interestingly, Cunha et al. also showed increased $\mathrm{q}_{\mathrm{p}}$ at lower $\mathrm{q}_{\mathrm{s}}$ and clearly stated that $\mathrm{q}_{\mathrm{s}}$ was the most important induction parameter. However, despite the obvious effect of $\mathrm{q}_{\mathrm{s}}$ on $\mathrm{q}_{\mathrm{p}}$, feeding profiles based on $\mathrm{q}_{\mathrm{s}}$ have not been tested yet.

Regardless of which control parameter is chosen to set up feeding profiles for fed batch cultivations, strain specific parameters have to be determined. This can either be done by continuous cultures [13] or by several, consecutive fed batch cultivations, which are operated at different parameter sets $[14,15]$. These methods have the disadvantage of being very time-consuming and labor-intensive. A robust method to determine these strain specific data and to develop a suitable feeding strategy in a shorter time period is of high interest in biotechnology to speed up process development and to quantitatively screen industrial relevant strains.

In this study, we developed a new and fast method to determine the strain specific data $\mathrm{q}_{\mathrm{s}}$ and $\mathrm{q}_{\mathrm{p}}$, as well as the adaptation time of the culture to the substrate methanol, based on easy to do batch cultivations with methanol pulses. The host $P$. pastoris and the product horseradish peroxidase (HRP) were used as a model system, for which we subsequently developed a novel feeding strategy solely based on the determined $\mathrm{q}_{\mathrm{s}}$ (Figure 1 ). Various fed batch cultivations, employing different $\mathrm{q}_{\mathrm{s}}$ feeding profiles, were carried out to characterize the strain, hence, to determine yields $\left(\mathrm{Y}_{\mathrm{X} / \mathrm{S}}, \mathrm{Y}_{\mathrm{CO} / \mathrm{S}}\right)$ and the specific productivity $\left(\mathrm{q}_{\mathrm{p}}\right)$ to evaluate and improve the feeding strategy. To our knowledge this is the first time that different dynamic feeding profiles only based on $\mathrm{q}_{\mathrm{s}}$ were tested to

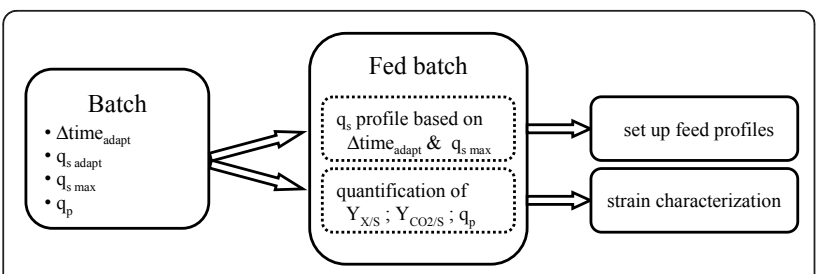

Figure 1 Experimental strategy for the determination of relevant strain specific parameters in a batch cultivation with methanol pulses. These strain specific data $\left(\Delta\right.$ time $_{\text {adapt }}$ - adaptation time; $q_{s}$ adapt - specific substrate uptake rate during the adaptation period; $q_{s}$ max - maximum specific substrate uptake rate) are then used to set up a feeding profile for $P$. pastoris in fed batch cultivations. The calculated yields $\left(Y_{X / Y}, Y_{\mathrm{CO} 2 / S}\right)$ and the specific productivity $\left(q_{p}\right)$ can consequently be used for strain characterization. develop a feeding strategy for $P$. pastoris aiming at increased productivity.

\section{Material and methods}

\section{Microorganism and recombinant protein}

The Pichia pastoris strain KM71 H (arg4 aox1:arg4) was transformed with a plasmid containing the gene for the horseradish peroxidase isoenzyme C1A (HRP) and was gratefully provided by Prof. Anton Glieder (Graz University of Technology, Austria). The phenotype of the strain corresponded to an AOX1-deficient clone which is characterized as $\mathrm{Mut}^{\mathrm{S}}$ (methanol utilization slow) and HRP was secreted into the fermentation broth.

Horseradish peroxidase is a member of the plant peroxidase super family [16] and catalyzes the oxidation of many substrates using hydrogen peroxide, resulting in oxidized products and in the formation of two molecules of water per molecule of hydrogen peroxide [17-19]. It is a heme-containing glycoprotein with a molecular weight of approximately $44 \mathrm{kDa}$ that has been studied for more than 100 years [19]. Horseradish peroxidase gains more and more industrial relevance in the past few years; it is used in waste water treatment [20,21], analytical diagnostics [22] and for the elimination of $\mathrm{H}_{2} \mathrm{O}_{2}$ from food and industrial wastewater [23].

\section{Stability of the enzyme horseradish peroxidase in the presence of methanol}

To check whether certain concentrations of methanol were affecting the stability of the enzyme horseradish peroxidase, HRP was diluted either in water or in BSM medium to a concentration of $1 \mathrm{U} / \mathrm{mL}$ and incubated in a waterbath at $28^{\circ} \mathrm{C}$ in the presence of up to $20 \mathrm{mg} / \mathrm{mL}$ methanol (which corresponds to $2.5 \% \mathrm{v} / \mathrm{v}$ ) overnight. At several time points samples were taken and analyzed for catalytic activity and protein content.

\section{Culture Media}

Preculture: Yeast nitrogen base media (YNBM), per liter: potassium phosphate buffer ( $\mathrm{pH}$ 6.0), 0.1 M; YNB w/o Amino acids and Ammonia Sulfate (Difco ${ }^{\mathrm{TM}}$ ), $3.4 \mathrm{~g}$; $\left(\mathrm{NH}_{4}\right)_{2} \mathrm{SO}_{4}, 10 \mathrm{~g}$; biotin, $400 \mathrm{mg}$; glucose, $20 \mathrm{~g}$.

Batch/fed batch: Basal salt media (BSM) [24], per liter: $85 \%$ phosphoric acid, $26.7 \mathrm{~mL} ; \mathrm{CaSO}_{4} \cdot 2 \mathrm{H}_{2} \mathrm{O}, 1.17 \mathrm{~g}$; $\mathrm{K}_{2} \mathrm{SO}_{4}, 18.2$ g; $\mathrm{MgSO}_{4} \cdot 7 \mathrm{H}_{2} \mathrm{O}, 14.9$ g; $\mathrm{KOH}, 4.13 \mathrm{~g}$; $\mathrm{C}_{6} \mathrm{H}_{12} \mathrm{O}_{6} \cdot \mathrm{H}_{2} \mathrm{O}$, 44 g, Antifoam Struktol J650, $0.2 \mathrm{~mL}$; PTM1, $4.35 \mathrm{~mL} ; \mathrm{NH}_{4} \mathrm{OH}$ as $\mathrm{N}$-source (see experimental procedure). Trace element solution (PTM1), per litre: $\mathrm{CuSO}_{4} \cdot 5 \mathrm{H}_{2} \mathrm{O}, 6.0$ g; NaI 0.08 g; $\mathrm{MnSO}_{4} \cdot \mathrm{H}_{2} \mathrm{O}, 3.0$ g; $\mathrm{Na}_{2} \mathrm{MoO}_{4} \cdot 2 \mathrm{H}_{2} \mathrm{O}, 0.2 \mathrm{~g} ; \mathrm{H}_{3} \mathrm{BO}_{3}, 0.02 \mathrm{~g} ; \mathrm{CoCl}_{2}, 0.5 \mathrm{~g}$; $\mathrm{ZnCl}_{2}, 20.0$ g; $\mathrm{FeSO}_{4} \cdot 7 \mathrm{H}_{2} \mathrm{O}, 65.0$ g; biotin, $0.2 \mathrm{~g}, \mathrm{H}_{2} \mathrm{SO}_{4}$, $5 \mathrm{~mL}$.

Feed glucose, per liter: glucose, 250 g; PTM1, $12 \mathrm{~mL}$, Struktol J650, $0.3 \mathrm{~mL}$. 
Feed methanol, per liter: methanol, 300 g; PTM1, 4 mL; Struktol J650, $0.3 \mathrm{~mL}$, induction period was carried out in presence of $\delta$-Aminolevulinic acid ( $\delta$-ALA), $1 \mathrm{mM}$.

Base: $\mathrm{NH}_{4} \mathrm{OH}$, concentration was determined by titration with $0.25 \mathrm{M}$ potassium hydrogen phthalate (KHP).

\section{Experimental Procedure Preculture}

Frozen stocks $\left(-80^{\circ} \mathrm{C}\right)$ were pre-cultivated in $100 \mathrm{~mL}$ of YNBM in $1000 \mathrm{~mL}$ shake flasks at $28^{\circ} \mathrm{C}$ and $200 \mathrm{rpm}$ for max. 24 hours. Then, the preculture was transferred aseptically to the respective culture vessel. The inoculation volume was approximately $10 \%$ of the final starting volume.

\section{Batch cultivation and determination of $q_{s}$}

Batch cultivations were carried out in a $1 \mathrm{~L}$ working volume glass bioreactor (Applikon, Netherlands). Basal salt media was sterilized in the bioreactor and $\mathrm{pH}$ was adjusted to $\mathrm{pH} 5.0$ by using concentrated ammonia solution after autoclaving. Sterile filtered trace elements were transferred to the reactor aseptically. Dissolved oxygen $\left(\mathrm{dO}_{2}\right)$ was measured with a sterilizable polarographic dissolved oxygen electrode (Mettler Toledo, Switzerland). The $\mathrm{pH}$ was measured with a sterilizable electrode (Mettler Toledo, Switzerland) and maintained constant with a step controller using ammonia solution (1 to $2 \mathrm{M}$ ). Base consumption was determined gravimetrically. Cultivation temperature was set to $28^{\circ} \mathrm{C}$ and agitation was fixed to $1200 \mathrm{rpm}$. The culture was aerated with $1.25 \mathrm{vvm}$ dried air and off-gas of the culture was measured by using an infrared cell for $\mathrm{CO}_{2}$ and a paramagnetic cell for $\mathrm{O}_{2}$ concentration (Servomax, Switzerland). Temperature, $\mathrm{pH}$, $\mathrm{dO}_{2}$, agitation as well as $\mathrm{CO}_{2}$ and $\mathrm{O}_{2}$ in the off-gas were measured online and logged in a process information management system (PIMS; Lucullus, Biospectra, Switzerland).

After the complete consumption of the substrate glucose, which was indicated by an increase of dissolved oxygen and a drop in off-gas activity, the first methanol pulse of a final concentration of $0.5 \%(\mathrm{v} / \mathrm{v})$ was conducted with pure methanol (supplemented with PTM1, $12 \mathrm{~mL} / \mathrm{L}$ of methanol). Following pulses were performed with $1 \%(\mathrm{v} / \mathrm{v})$, before a last pulse with $2 \%(\mathrm{v} / \mathrm{v})$ final concentration of methanol was carried out. To investigate the metabolic activity during methanol excess and also the dynamic behavior of the cell metabolism after methanol limitation for several hours, the pulse experiments were performed like this: after methanol was depleted after the "first" pulse (followed by off-gas analysis), an immediate "second" methanol pulse with the same concentration was conducted per day. After methanol depletion, methanol starvation was carried out for several hours before another so-called "first" pulse was applied (Figure 2).

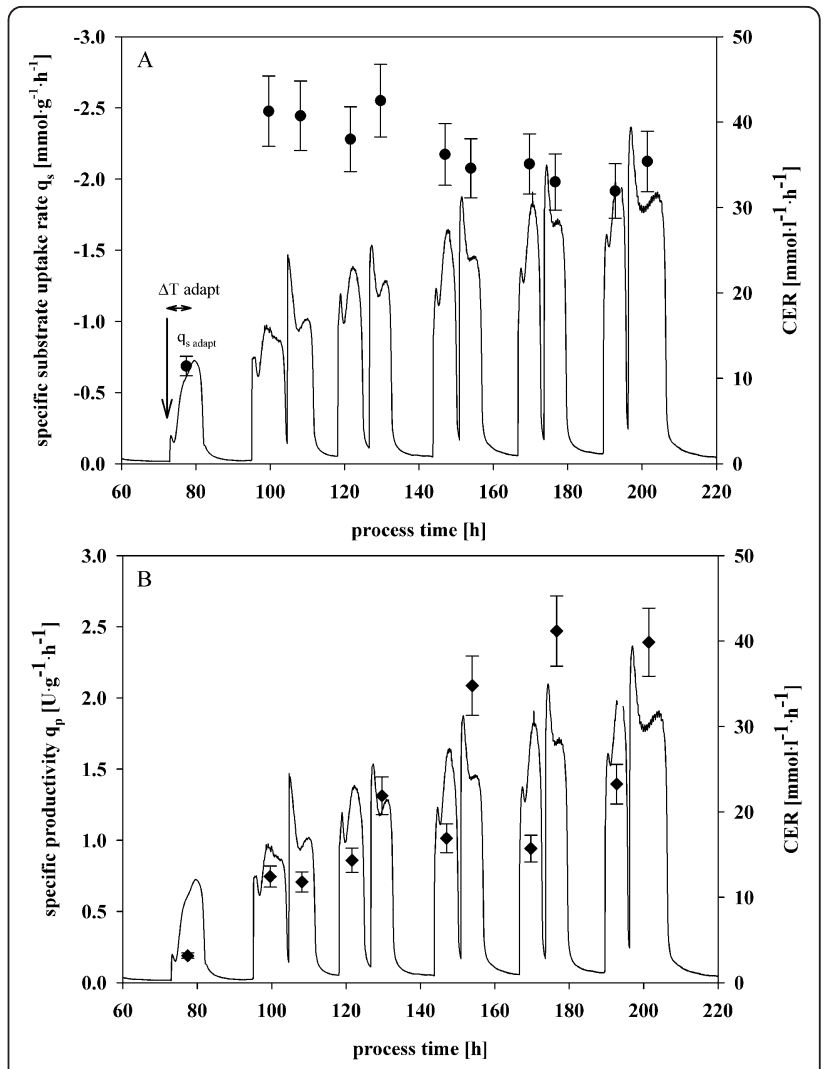

Figure 2 Batch cultivation with methanol pulses of $0.5,1$ and $2 \%(\mathbf{v} / \mathbf{v})$. A, calculated specific substrate uptake rate $q_{s}$ (circle) and carbon dioxide evolution rate (CER); $B$, specific production rate $q_{p}$ (diamond) and carbon dioxide evolution rate (CER).

For each pulse, at least two samples were taken to determine the concentrations of substrate and product as well as dry cell weight and $\mathrm{OD}_{600}$ to calculate the specific substrate uptake rate $\mathrm{q}_{\mathrm{s}}$.

\section{Fed batch cultivations}

Fed batch cultures were carried out in a $7.5 \mathrm{~L}(5 \mathrm{~L}$ working volume) glass bioreactor (Infors, Switzerland). Concentrated BSM medium (2-fold concentrated to supply necessary salts for high cell densities) was sterilized in the bioreactor and $\mathrm{pH}$ was adjusted to $\mathrm{pH} 5.0$ by using concentrated ammonia solution after autoclaving. The initial volume was set to $1.5 \mathrm{~L}$. Trace elements were filter sterilized and transferred to the reactor aseptically. Dissolved oxygen was measured with a sterilizable polarographic dissolved oxygen electrode (Hamilton, Switzerland). The $\mathrm{pH}$ was measured with a sterilizable electrode (Hamilton, Switzerland) and maintained constant using ammonia solution ( 3 to $5 \mathrm{M}$ ). Agitation was set to $1500 \mathrm{rpm}$. The culture was aerated with at least $1 \mathrm{vvm}$ to avoid oxygen limitation. The dissolved oxygen signal was used to adjust air-in flow manually to keep levels $>30 \% \mathrm{dO}_{2}$ at all time points. In case air flow was limited, pure oxygen was added. $\mathrm{CO}_{2}$ 
and $\mathrm{O}_{2}$ were measured as described above. Base consumption and reactor weight were measured gravimetrically. The fed batch feed was measured and controlled using a gravimetrically based PID flow controller.

At several time points during fed batch cultivations, samples were taken and analyzed for accumulated methanol, biomass concentration (dry cell weight and optical density $\mathrm{OD}_{600}$ ), protein content and enzymatic activity. Based on the total biomass content, feed rates were adjusted manually corresponding to the defined $\mathrm{q}_{\mathrm{s}}$ setpoint.

Three different fed batch strategies were tested: fed batch $\mathrm{A}$, where methanol was adjusted to a constant flow during the whole induction phase; fed batch $\mathrm{B}$, where after the adaption time with a $\mathrm{q}_{\mathrm{s} \text { adapt }}$, a shift to a high substrate uptake rate of $\sim 90 \%$ of $\mathrm{q}_{\mathrm{s} \text { max }}$ was done and adjustments to the very same $\mathrm{q}_{\mathrm{s}}$ set point during cultivation were performed repeatedly; and fed batches $\mathrm{C} 1$ and $\mathrm{C} 2$, where after the adaptation period with $\mathrm{q}_{\mathrm{s}}$ adapt, the methanol flow was stepwise increased up to $\mathrm{q}_{\mathrm{s}}$ $\max$. Values for $\mathrm{q}_{\mathrm{s} \text { adapt }}$ and $\mathrm{q}_{\mathrm{s} \text { max }}$ had been determined in batch experiments (vide supra). An overview of the fed batch cultivations and the corresponding settings is given in Table 1.

\section{Analysis of growth- and expression-parameters}

Dry cell weight (DCW) was determined by centrifugation of $5 \mathrm{~mL}$ culture broth $\left(5000 \mathrm{rpm}, 4^{\circ} \mathrm{C}, 10 \mathrm{~min}\right)$ in a laboratory centrifuge (Sigma $4 \mathrm{~K} 15$, rotor 11156), washing the pellet with $5 \mathrm{~mL}$ deionized water and subsequent drying at $105^{\circ} \mathrm{C}$ to a constant weight in an oven. Optical density of the culture broth was measured using a spectrophotometer (U-1100 Hitachi, Japan) at a wavelength of $600 \mathrm{~nm}\left(\mathrm{OD}_{600}\right)$. Correlation between dry cell weight measurement and $\mathrm{OD}_{600}$ showed a coefficient of regression of $R^{2}=0.997$ over the full concentration range (data not shown) and could therefore be used for $\mathrm{q}_{\mathrm{s}}$ adaptation.

The activity of HRP was determined using a CuBiAn $\mathrm{XC}$ enzymatic robot (Innovatis, Germany). Cell free samples $(10 \mu \mathrm{l})$ were added to $140 \mu \mathrm{l}$ of $1 \mathrm{mM}$ ABTS (2.2' azino bis 3-ethylbenzthiazoline-6-sulphonic acid) prepared in $50 \mathrm{mM} \mathrm{NaOAc}$ buffer $(\mathrm{pH} 4.5)$. The reaction mixture was incubated at $37^{\circ} \mathrm{C}$ and was started by the addition of $20 \mu \mathrm{l}$ of $0.075 \% \mathrm{H}_{2} \mathrm{O}_{2}$. Changes of absorbance at $415 \mathrm{~nm}$ were measured for 80 seconds and rates were calculated. Calibration was done using commercially available horseradish peroxidase (Type VI-A, Sigma-Aldrich, P6782, Lot\# 118K76703) as standard at six different concentrations $(0.02 ; 0.05 ; 0.1 ; 0.25 ; 0.5$ and $1.0 \mathrm{U} / \mathrm{mL}$ ). Samples with high enzymatic activity were automatically diluted by the system. Protein concentrations were determined at $595 \mathrm{~nm}$ by the Bradford assay [25] using the BioRad Protein Assay Kit with BSA as standard.

\section{Substrate concentrations}

Concentrations of methanol were determined in cell free samples by HPLC (Agilent Technologies, USA) equipped with a Supelcoguard column, a Supelcogel C$610 \mathrm{H}$ ion-exchange column (Sigma-Aldrich, USA) and a refractive index detector (Agilent Technologies, USA). The mobile phase was $0.1 \% \mathrm{H}_{3} \mathrm{PO}_{4}$ with a constant flow rate of $0.5 \mathrm{~mL} / \mathrm{min}$ and the system was run isocratic. Calibration was done by measuring standard points in the range of 0.1 to $10 \mathrm{~g} / \mathrm{L}$ methanol.

Concentrations of glucose were determined in cell free samples by a commercial enzymatic assay kit using the $\mathrm{CuBiAN}$ XC enzymatic robot (Innovatis, Germany). Calibration was done with 4 standard points in the range from 0 to $3 \mathrm{~g} / \mathrm{L}$ glucose. Samples with higher glucose concentration were diluted automatically by the system.

\section{Data analysis}

Measurements of biomass concentration, product concentration and substrate concentration were executed in duplicates: along the observed standard deviation for the single measurement, the error was propagated to the specific rates $\mathrm{q}_{\mathrm{s}}$ and $\mathrm{q}_{\mathrm{p}}$ as well as to the yield coefficients. The error of determination of the specific rates and the yields was therefore set to $10 \%$ and $5 \%$, respectively.

\section{Electrophoresis}

To check the purity of the excreted HRP, electrophoresis was done with aliquots of supernatants obtained at different time points during the cultivation of $P$. pastoris

Table 1 Description of feeding strategies for fed batch cultivations based on the specific substrate uptake rate $q_{s}$

\begin{tabular}{|c|c|c|}
\hline $\begin{array}{l}\text { Fed batch } \\
\text { name }\end{array}$ & Symbol & Description of the strategy \\
\hline Fed batch A & $\Delta$ & conventional feeding strategy: long adaptation time and initially adjusted, constant flow rate \\
\hline Fed batch B & $\bullet$ & $\begin{array}{c}\text { short adaptation time (out of batch exp.) and adjustment to high uptake rate }\left(90 \% \text { of } \mathrm{q}_{\mathrm{s} \max }\right) \text { with repeated } \\
\text { readjustments }\end{array}$ \\
\hline Fed batch C1 & $\mathbf{v}$ & short adaptation time (out of batch exp.) and stepwise adjustment of $\mathrm{q}_{\mathrm{s}}$ until $\mathrm{q}_{\mathrm{s} \text { max }}$ with repeated readjustments \\
\hline Fed batch C2 & $\bullet$ & \\
\hline
\end{tabular}


expressing the hrp gene extracellularly as described by Laemmli et al. [26]. SDS-PAGE was performed using a $5 \%$ stacking gel and a $10 \%$ separating gel in $1 \times$ Trisglycine buffer. Gels were run in the vertical electrophoresis Mini-PROTEAN Tetra Cell apparatus (Biorad; Vienna, Austria) at $150 \mathrm{~V}$ for about $2 \mathrm{~h}$. Gels were stained with Coomassie blue. The protein mass standard used was the PageRuler Prestained Ladder (Fermentas; Vienna, Austria).

\section{Results and Discussion}

Stability of the enzyme horseradish peroxidase in the presence of methanol

To check whether the enzyme horseradish peroxidase denatures at certain concentrations of methanol, HRP was incubated in the presence of methanol concentrations of up to $2.5 \%(\mathrm{v} / \mathrm{v})$ at $28^{\circ} \mathrm{C}$ overnight. No loss in catalytic activity and protein content was detected after this incubation, which is why methanol pulses in batch experiments with concentrations of up to $2.5 \%(\mathrm{v} / \mathrm{v})$ were theoretically possible without any denaturing effects on HRP.

Determination of strain specific parameters by easy to do batch cultivations with methanol pulses

After depletion of glucose in batch cultivations, a first methanol adaption pulse with a final concentration of $0.5 \%(\mathrm{v} / \mathrm{v})$ was applied. The adaptation time to the new substrate methanol $\left(\Delta\right.$ time $\left._{\text {adapt }}\right)$ was determined with 7 hours and was defined by the detection of a maximum in off-gas activity (Figure 2A).

The calculated carbon dioxide evolution rate (CER), signifying metabolic activity, allowed to distinguish different states within the methanol pulses with local minima and maxima (Figure 2). This metabolic behavior of the cells results from inhibition and regulation events in transient conditions, caused by intracellular components like e.g. produced $\mathrm{H}_{2} \mathrm{O}_{2}$, and transport actions, and has been described for various systems in literature before [27-29].

The high frequent determination of biomass, methanol and product concentrations allowed specific rate calculations for methanol uptake $\mathrm{q}_{\mathrm{s}}$ and productivity $\mathrm{q}_{\mathrm{p}}$ during the methanol pulses. Specific substrate uptake rates were calculated with $0.8 \pm 0.08 \mathrm{mmol} \cdot \mathrm{g}^{-1} \cdot \mathrm{h}^{-1}$ in the adaptation period $\left(\mathrm{q}_{\mathrm{s} \text { adapt }}\right)$ and with around $2 \pm 0.20 \mathrm{mmol} \cdot \mathrm{g}^{-1} \cdot \mathrm{h}^{-1}$ as a maximum during pulses $\left(\mathrm{q}_{\mathrm{s} \text { max }}\right)$. No difference in the calculated $\mathrm{q}_{\mathrm{s}}$ between the "first" and the subsequent "second" pulse on a respective day was observed (Figure 2A). In contrast, the calculated values for $\mathrm{q}_{\mathrm{p}}$ (Figure $2 \mathrm{~B}$ ) were very different between the first and the subsequent second pulse. During the first pulse specific productivities of maximum $1.3 \pm 0.13 \mathrm{U} \cdot \mathrm{g}^{-1} \cdot \mathrm{h}^{-1}$ were observed, whereas during the second pulse an increased specific productivity of up to $2.5 \pm 0.25 \mathrm{U} \cdot \mathrm{g}^{-1} \cdot \mathrm{h}^{-1}$ was measured. This increased productivity during the second methanol pulse may be due to the fact that no adaption of the cells to methanol was necessary because all metabolic key functions for methanol assimilation remained in an active state. Thus, recombinant protein expression could start directly and energy was used more efficiently for product formation. This result shows clearly that Pichia cultures should be kept induced at all time to obtain maximal productivity. Interestingly, $\mathrm{q}_{\mathrm{p}}$ also increased over time for first and second pulses, respectively (Figure 2B). Methanol pulses, where the same final concentration of methanol was used, but which were conducted in the later phase of the batch cultivation, showed higher specific productivities compared to pulses before. Obviously, the culture exhibited a "memory effect" and thus a timedependence of $q_{p}$ could be observed in the batch experiment.

As we show here, batch cultivations with methanol pulses allowed a fast identification of strain specific parameters, which are crucial for subsequent fed batch cultivations. The determined maximum specific substrate uptake rate $\mathrm{q}_{\mathrm{s} \text { max }}$, represents the upper end of the feed profile respective to $\mathrm{q}_{\mathrm{s}}$. This novel method has the advantage of being less time-consuming and laborintensive compared to the traditional methods, like continuous cultivations, and additionally allows a free choice of substrate, like e.g. the 2 to 3-fold cheaper glucose instead of glycerol.

\section{Fed batch feeding strategy based on $\mathrm{q}_{\mathrm{s}}$}

Based on the batch results, we performed several fed batch cultivations with different feeding profiles based on the specific substrate uptake rate $\mathrm{q}_{\mathrm{s}}$, to find a feeding strategy for a recombinant $P$. pastoris strain.

\section{Feeding profiles}

After a batch phase on glucose as substrate (volume 1.5 L), an exponential fed batch cultivation with glucose yielded in biomass concentrations of up to $70 \mathrm{~g} / \mathrm{L}$ in a volume of $2.5 \mathrm{~L}$. At the end of this fed batch phase, a sample was taken to determine the current biomass concentration by measuring the $\mathrm{OD}_{600}$ and the $\mathrm{DCW}$.

Based on the calculated specific methanol uptake rate during adaptation $\left(\mathrm{q}_{\mathrm{s} \text { adapt }}\right)$ from the batch experiment, which was around $0.8 \pm 0.08 \mathrm{mmol} \cdot \mathrm{g}^{-1} \cdot \mathrm{h}^{-1}$, we used a litthe bit lower $\mathrm{q}_{\mathrm{s} \text { adapt }}$ of $0.5 \mathrm{mmol} \cdot \mathrm{g}^{-1} \cdot \mathrm{h}^{-1}$ methanol for the fed batch cultivations during the adaption time. After $\Delta$ time $_{\text {adapt }}$, three different feeding strategies (fed batches $\mathrm{A}, \mathrm{B}$ and $\mathrm{C} 1 / \mathrm{C} 2$ ) were tested and compared (Figure 3 Table 1).

For fed batch A, which described a conventional feeding strategy as in the Invitrogen protocol, the methanol feed was adjusted to a substrate uptake rate of 1.0 $\mathrm{mmol} \cdot \mathrm{g}^{-1} \cdot \mathrm{h}^{-1}$. The adjustment just happened at the 


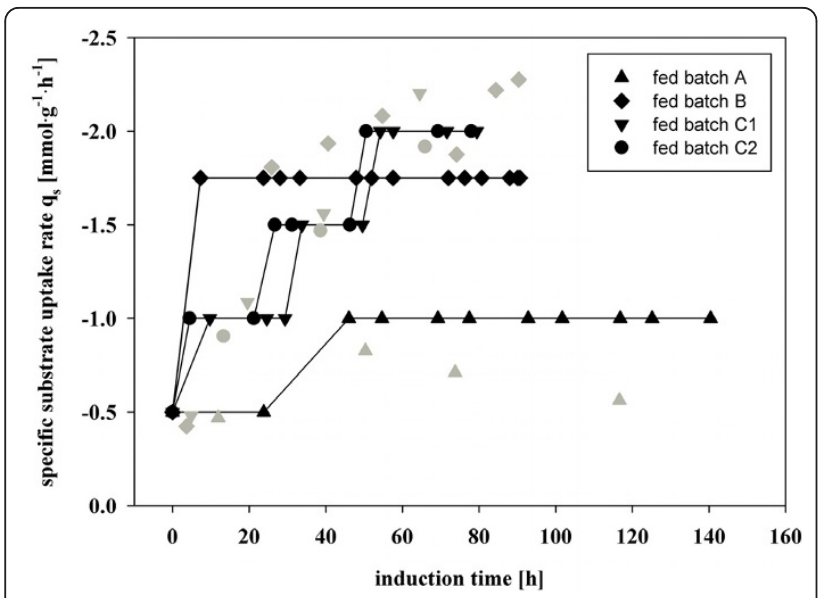

Figure 3 Specific substrate uptake rate profiles which were used for different fed batch cultivations. Theoretical $q_{s}$ fed batch A (black triangle up), offline determined $\mathrm{q}_{\mathrm{s}}$ fed batch A (grey triangle up); theoretical $q_{s}$ fed batch $B$ (black diamond), offline determined $q_{s}$ fed batch $B$ (grey diamond); theoretical $q_{s}$ fed batch $\mathrm{C} 1$ (black triangle down), offline determined $\mathrm{q}_{\mathrm{s}}$ fed batch C1 (grey triangle down); theoretical $\mathrm{q}_{\mathrm{s}}$ fed batch C2 (black circle), offline determined $q_{s}$ fed batch C2 (grey circle). The error of determination for offline $\mathrm{q}_{\mathrm{s}}(10 \%)$ is not shown for better readability.

beginning and no further readjustments of the feeding rate were performed during the cultivation. Consequently, as biomass still increased, a drop down of $\mathrm{q}_{\mathrm{s}}$ over time was observed (Figure 3).

In the other fed batch experiments $\mathrm{B}, \mathrm{C} 1$ and $\mathrm{C} 2$ adjustments of $\mathrm{q}_{\mathrm{s}}$ were done after each sampling, based on $\mathrm{OD}_{600}$ measurements. As shown in Figure 3 the effective $\mathrm{q}_{\mathrm{s}}$, determined by off-line sampling, and the designated $\mathrm{q}_{\mathrm{s}}$ in these fed batch cultivations were very similar. Thus, a frequent determination of the actual biomass concentration in the reactor vessel is necessary, to be able to adjust the feeding rate to the chosen $\mathrm{q}_{\mathrm{s}}$. The development of robust measurement devices for the online determination of the biomass concentration, as e. g. FTIR, capacity probes or soft sensors, could allow an online adjustment of the feeding rate to $\mathrm{q}_{\mathrm{s}}$ by an automatic control system in the future, and thus the laborintensive, frequent sampling procedure would be unnecessary.

\section{Maintenance metabolism vs. cell growth}

The relationship between $\mathrm{q}_{\mathrm{s}}$ and the specific growth rate was tested and found to be linearly correlated (data not shown). Based on this, the maintenance coefficient for this $P$. pastoris strain could be determined with around $0.5 \mathrm{mmol} \cdot \mathrm{g}^{-1} \cdot \mathrm{h}^{-1}$ (which equals $0.016 \mathrm{~g} \cdot \mathrm{g}^{-1} \cdot \mathrm{h}^{-1}$ ). Very similar results were reported by Jahic et al. for fed batch cultures using $P$. pastoris expressing a fusion protein [5] with a maintenance coefficient of $0.013 \mathrm{~g} \cdot \mathrm{g}^{-1} \cdot \mathrm{h}^{-1}$. When we adjusted $\mathrm{q}_{\mathrm{s}}$ to values higher than $1.0 \mathrm{mmol} \cdot \mathrm{g}^{-1} \cdot \mathrm{h}^{-1}$, we observed a significant increase in $\mathrm{Y}_{\mathrm{X} / \mathrm{S}}$ and a corresponding decrease in $\mathrm{Y}_{\mathrm{CO} 2 / \mathrm{S}}$ (Figure 4). That means that at $\mathrm{q}_{\mathrm{s}}$ of $<1.0 \mathrm{mmol} \cdot \mathrm{g}^{-1} \cdot \mathrm{h}^{-1}$ most of the energy is obviously used for maintenance metabolism of the cells and thus for the production of $\mathrm{CO}_{2}$ and not for cell growth or protein production. Interestingly, the same effect on biomass yield was observed by d'Anjou et al. using a continuous culture system with a mixed feed strategy [13]. However, we were able to extract this information from time-efficient, dynamic experiments equivalently. Consequently, we employed specific substrate uptake rates of $>1.0 \mathrm{mmol} \cdot \mathrm{g}^{-1} \cdot \mathrm{h}^{-1}$ to guarantee a sufficient amount of energy for both, maintenance and cell growth.

\section{Required methanol concentration for induction - a principle} question

When producing recombinant proteins with P. pastoris, the principle question is how much methanol has to be fed to guarantee a fully induced AOX promoter. A lot of different studies have examined this topic, with different results. D'Anjou et al., for example, reported that a methanol concentration between 1 and $2 \mathrm{~g} / \mathrm{L}$ should be maintained in the culture to guarantee fully induced heterologous protein production [13]. Another study of the methanol concentration and its effect on P. pastoris $\mathrm{Mut}^{\mathrm{S}}$ strains was done by Kupcsulik and Sevella, who showed that the specific productivity of a recombinant human serum albumin expression system showed a maximum at $0.45 \mathrm{~g} / \mathrm{L}$ of methanol [30]. In contrast to those studies, Cregg reported an even stronger induction of the AOX promoter in limited conditions [31], which

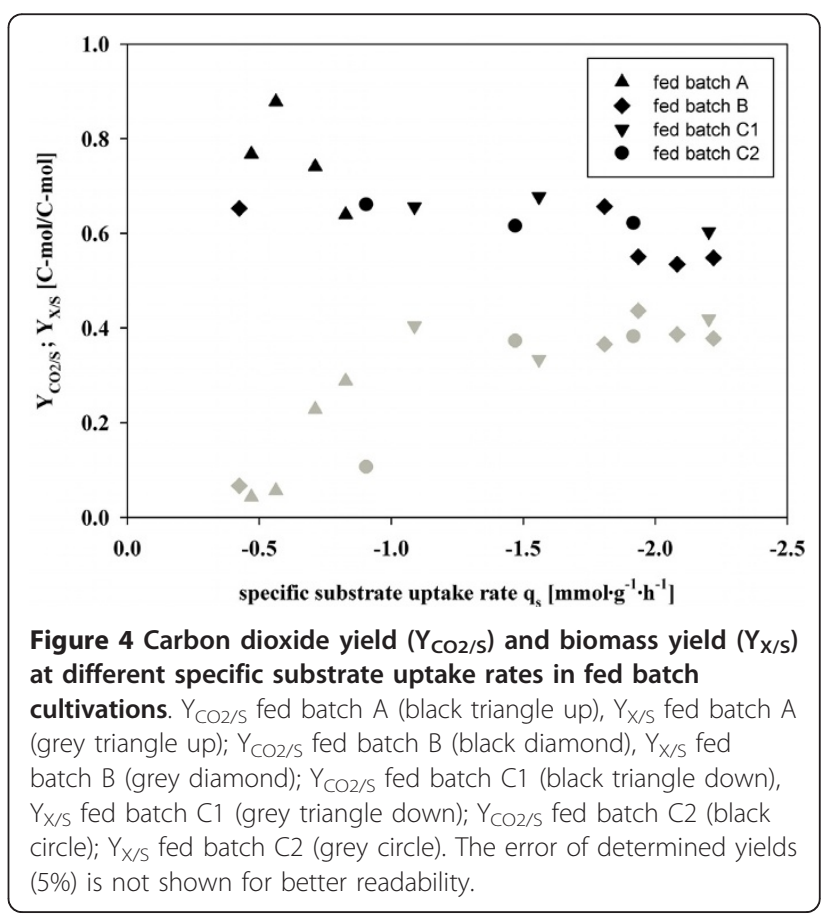


was the basis for several following studies applying a limited methanol supply for induction [1-3].

For all described fed batch strategies in our study, no significant methanol accumulation was detected (detection limit $0.1 \mathrm{~g} / \mathrm{L}$ ). We clearly show that high residual concentrations of methanol during the production phase are not required for the induction of the $P$. pastoris $\mathrm{Mut}^{\mathrm{S}}$ strain, as even higher specific productivities were obtained in limited fed batches with constant substrate uptake rates, compared to the batch cultivations with high methanol concentrations applied in the pulseexperiments (Table 2).

Extracellular protein production and specific productivity $q_{p}$ To follow the formation of excreted horseradish peroxidase (HRP) during the induction phase, SDS-PAGE analyses with cell-free supernatants were performed. SDSPAGE analysis (Coomassie staining, Figure 5) of the cultivation broth taken at different time points did not show a distinct band for HRP, but rather a smear between $60-65 \mathrm{kDa}$. The difference between the reported molecular weight of around $44 \mathrm{kDa}$ for HRP and the observed molecular weight in this study results from the high degree of glycosylation of the recombinant protein expressed in $P$. pastoris with mannose-type oligosaccharides, as described previously for HRP by Morawski et al. [32].

The protein content in the cultivation broth increased over time from $0.052 \mathrm{mg} / \mathrm{mL}$ after the fed-batch phase with glucose to $0.243 \mathrm{mg} / \mathrm{mL}$ at the end of the cultivation, which were around 91 hours of induction. As shown in Figure 5 the increase of the protein content in the cultivation broth is ascribed to an increased amount of HRP, which constituted the majority of secreted proteins in the cultivation broth.

Based on the determined biomass content and the enzymatic activity, the specific productivity $\mathrm{q}_{\mathrm{p}}$ during the different fed batch cultivations was calculated. The lowest $\mathrm{q}_{\mathrm{p}}$ was obtained in fed batch $\mathrm{A}$, which described a conventional feeding strategy, where also the lowest $\mathrm{q}_{\mathrm{s}}$ was used and was not adapted over time (Figure 6). In fed batch $\mathrm{B}$, which considered the actual biomass concentration and where the $\mathrm{q}_{\mathrm{s}}$ of $1.75 \mathrm{mmol} \cdot \mathrm{g}^{-1} \cdot \mathrm{h}^{-1}$ was adapted regularly over time and thus the cells were kept in a certain physiological state, a 2 -fold increase in $\mathrm{q}_{\mathrm{p}}$

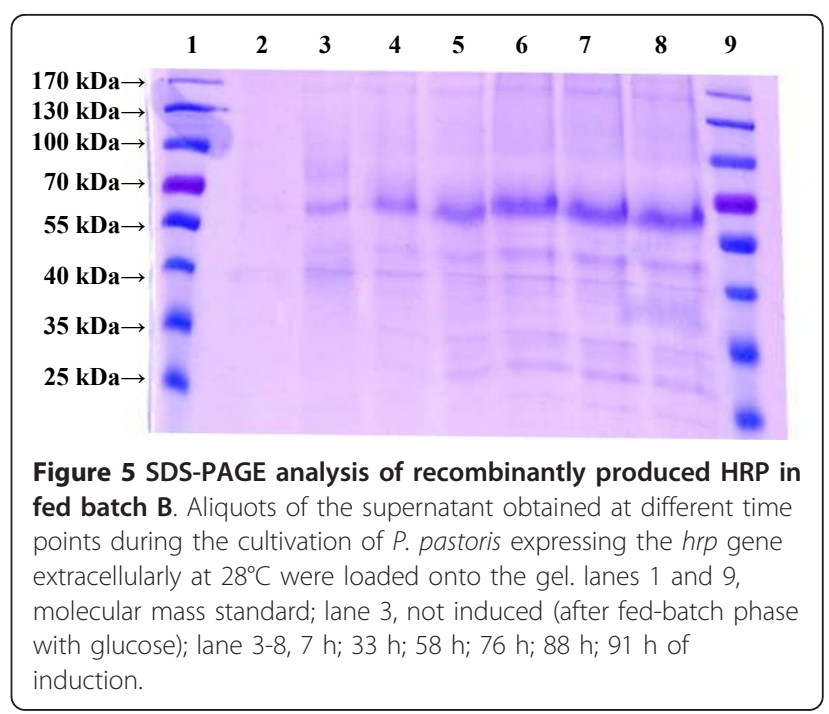

was observed. Clearly, a higher $\mathrm{q}_{\mathrm{s}}$ resulted in a higher $\mathrm{q}_{\mathrm{p}}$, which disagrees with the results obtained by Khatri and Hoffmann and Cunha et al. [10,11], who stated that lower $\mathrm{q}_{\mathrm{s}}$ resulted in higher protein production.

However, a dynamic, stepwise feeding strategy resulted in an even higher productivity compared to the other strategies tested (Figure 6). This dynamic feeding strategy considered $\mathrm{q}_{\mathrm{s} \text { max }}$, which had been determined in the batch experiment, as the highest possible substrate uptake rate of the cells, as well as the yield coefficients and the maintenance coefficient as the lower end of efficient energy usage. The feed profile was set up in a way to head off as quickly as possible from the maintenance state of the cells (hence $\mathrm{q}_{\mathrm{s}}$ was set to values $\geq 1.0$ $\left.\mathrm{mmol} \cdot \mathrm{g}^{-1} \cdot \mathrm{h}^{-1}\right)$, before $\mathrm{q}_{\mathrm{s}}$ was dynamically adapted in steps to $\mathrm{q}_{\mathrm{s} \max }$. In fed batch cultivations $\mathrm{C} 1$ and $\mathrm{C} 2$, where this dynamic feeding strategy was applied, a $\mathrm{q}_{\mathrm{p}}$ of around $11 \pm 0.11 \mathrm{U} \cdot \mathrm{g}^{-1} \cdot \mathrm{h}^{-1}$ was determined, which represents a 5.5 -fold increase compared to fed batch A.

\section{Time adaptation}

The fact that there was still a more than 2-fold difference in $\mathrm{q}_{\mathrm{p}}$ between fed batches $\mathrm{C} 1 / \mathrm{C} 2$, where $\mathrm{q}_{\mathrm{s}}$ was increased stepwise, and fed batch $\mathrm{B}$, where immediately after the adaption period a high $\mathrm{q}_{\mathrm{s}}$ of $1.75 \mathrm{mmol} \cdot \mathrm{g}^{-1} \cdot \mathrm{h}^{-1}$ was applied, indicated another factor being crucial for

Table 2 Comparison of the specific substrate uptake rates $q_{s}$ and determined maximum specific productivities $q_{p}$

\begin{tabular}{|c|c|c|c|}
\hline Experiment $^{\mathrm{a}}$ & Methanol concentration & Specific substrate uptake rate $\mathrm{q}_{\mathrm{s}}\left[\mathrm{mmol} \cdot \mathrm{g}^{-1} \cdot \mathrm{h}^{-1}\right]$ & Specific productivity $q_{p}\left[U \cdot g^{-1} \cdot h^{-1}\right]$ \\
\hline Batch with methanol pulses & from 0 to $16 \mathrm{~g} / \mathrm{L}$ & $\sim 2$ & $2.5 \pm 0.25$ \\
\hline Fed batch A $\Delta$ & limited & $<1$ & $2.0 \pm 0.20$ \\
\hline Fed batch B • & limited & 1.75 & $5.0 \pm 0.50$ \\
\hline Fed batch C1 $\mathbf{v}$ & limited & stepwise up to 2 & $10 \pm 0.10$ \\
\hline Fed batch C2 $\bullet$ & limited & stepwise up to 2 & $11 \pm 0.11$ \\
\hline
\end{tabular}

\footnotetext{
all experiments were performed in the presence of different concentrations of the inducer methanol.
} 


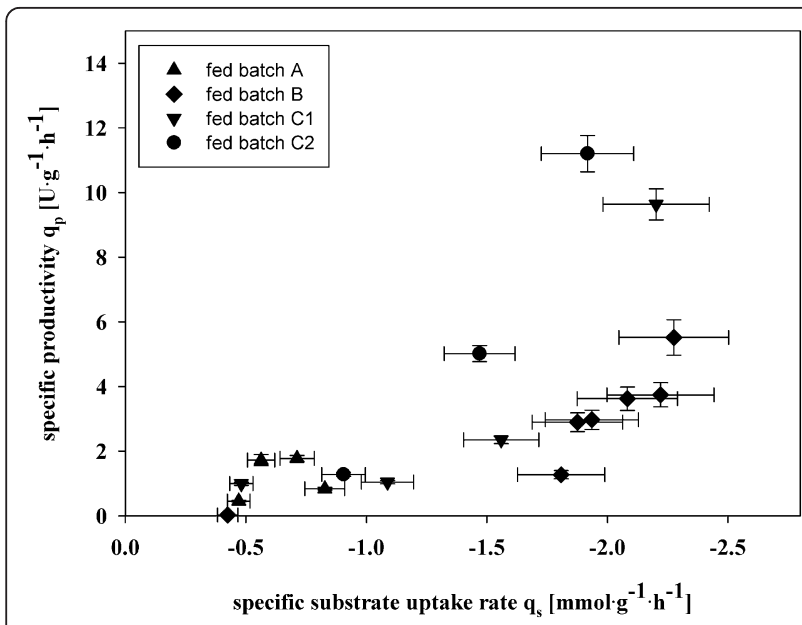

Figure 6 Specific productivity $\left(q_{p}\right)$ plotted against the specific substrate uptake rate $\left(\mathbf{q}_{\mathbf{s}}\right)$. Fed batch $A$ (triangle up); fed batch $B$ (diamond); fed batch C1 (triangle down); fed batch C2 (circle).

the specific productivity besides $\mathrm{q}_{\mathrm{s}}$. Therefore, the specific productivity $\mathrm{q}_{\mathrm{p}}$ was plotted against the induction time, to analyze possible time-dependent effects (Figure 7). Fed batch A and B were characterized by a linear increase of $\mathrm{q}_{\mathrm{p}}$ over time (fed batch $\mathrm{B}$ was characterized by a significant steeper slope), whereas fed batches $\mathrm{C} 1$ and $\mathrm{C} 2$ even showed an exponential increase of the specific productivity. It became obvious that the productivity was directly correlated to the induction time for all experiments conducted in this study, even in the batch experiments (Figure 2). Plantz et al. have recently reported an influence of the induction time on $\mathrm{q}_{\mathrm{p}}$ as well. They showed increasing product yields for the recombinant production of an interferon with $P$. pastoris in the first period of induction, but a subsequent decrease in product formation and a shift of the energy transfer towards biomass growth during the later phase of the cultivation [8]. In contrast to the study of Plantz et al., we clearly showed an increase of $\mathrm{q}_{\mathrm{p}}$ over the whole induction time for all experiments in this study (Figure 7).

Furthermore, fed batches $\mathrm{C} 1$ and $\mathrm{C} 2$ were characterized by an exponential increase of $\mathrm{q}_{\mathrm{p}}$ over time, in contrast to a linear increase for fed batches A and B (Figure 7). Obviously, a feeding strategy starting with a lower $\mathrm{q}_{\mathrm{s}}$ at the beginning of the induction phase, followed by a subsequent increase with a stepwise, dynamic feeding profile until $\mathrm{q}_{\mathrm{s} \text { max }}$ (fed batch $\mathrm{C} 1$ and $\mathrm{C} 2$ ), was superior to a feeding strategy, where immediately after the $\Delta$ time $_{\text {adapt }}$ a high $\mathrm{q}_{\mathrm{s}}$ was applied and kept constant (fed batch $\mathrm{B}$ ). When the cells had the time to undergo a dynamic, physiological adaptation to the current culture condition before $\mathrm{q}_{\mathrm{s}}$ was increased, a boost in $\mathrm{q}_{\mathrm{p}}$ was observed, which probably cannot be triggered by constant or exponential feeding regimes (Table 2).

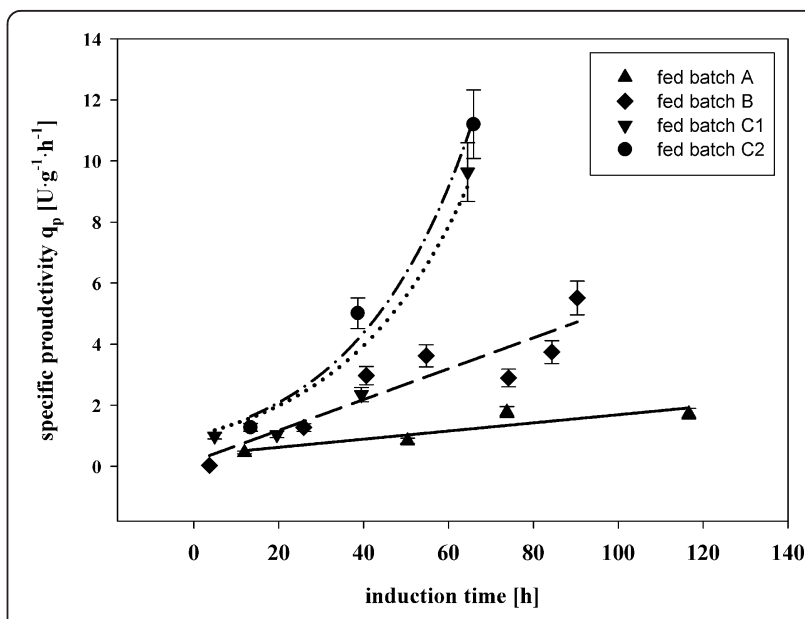

Figure 7 Specific productivity $\left(q_{p}\right)$ in fed batch cultures over the induction time. Fed batch A (triangle up); fed batch B (diamond); fed batch C1 (triangle down); fed batch C2 (circle). Regression lines: linear regression for fed batch $\mathrm{A}$ (continuous line); linear regression for fed batch B (discontinuous line); exponential regression for fed batch C1 (dotted line); exponential regression for fed batch C2 (dashed-dotted line).

Summarizing, we showed a clear time dependent trajectory for specific product formation, as $\mathrm{q}_{\mathrm{p}}$ increased over induction time for all experiments in this study. A tool for the early identification of this effect is of utmost importance in order to consistently compare different feeding profiles.

\section{Conclusions}

In this study, we developed a fast and easy to do method based on batch cultivations with methanol pulses to determine strain specific parameters of a $P$. pastoris $\mathrm{Mut}^{\mathrm{S}}$ strain expressing the enzyme horseradish peroxidase. A subsequently developed dynamic feeding strategy solely based on $\mathrm{q}_{\mathrm{s}}$, where the cells on the one hand had time to adapt to culture conditions, but were then challenged again repeatedly by a stepwise increase of $\mathrm{q}_{\mathrm{s}}$ up to $\mathrm{q}_{\mathrm{s} \text { max }}$, resulted in the highest $\mathrm{q}_{\mathrm{p}}$ compared to the other strategies tested. Hence, dynamic feeding profiles turned out to be a valuable method to boost the specific productivity. This calls for increased use of dynamic process conditions even for industrial feed profiles. We strongly believe that the strategy presented here can be successfully applied on other microbial expression systems, which is why we are currently testing the applicability of our novel, dynamic approach on other expression systems, like E. coli, and other products.

\section{Abbreviations}

$\Delta$ time $_{\text {adapt }}$ : time for adaptation of the culture to the new substrate (methanol) [h]; $\mu$ specific growth rate $\left[\mathrm{h}^{-1}\right]$; CER: carbon dioxide evolution 
rate $\left[\mathrm{mmol} \cdot \mathrm{L}^{-1} \cdot \mathrm{h}^{-1}\right]$; HRP: horseradish peroxidase; Mut ${ }^{\mathrm{S}}$ : methanol utilization slow phenotype; PID: proportional-integrative-derivative controller; $\mathrm{q}_{\mathrm{p}}$ : specific productivity of horseradish peroxidase $\left[U \cdot g^{-1} \cdot h^{-1}\right]$; $q_{s}$ : specific substrate uptake rate $\left[\mathrm{mmol} \cdot \mathrm{g}^{-1} \cdot \mathrm{h}^{-1}\right]$; $\mathrm{q}_{\mathrm{s}}$ adapt: specific substrate uptake rate during adaptation $\left[\mathrm{mmol} \cdot \mathrm{g}^{-1} \cdot \mathrm{h}^{-1}\right]$; $\mathrm{q}_{\mathrm{s}}$ max: maximum specific substrate uptake rate $\left[\mathrm{mmol} \cdot \mathrm{g}^{-1} \cdot \mathrm{h}^{-1}\right]$; rpm: rounds per minute; vvm: volume gas flow per volume liquid per minute; $Y_{\text {COz/s: }}$ : yield coefficient of carbon dioxide

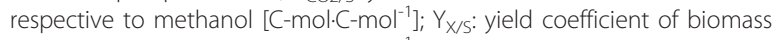

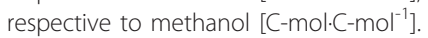

\section{Acknowledgements}

The authors are very grateful to Prof. Anton Glieder and his workgroup for providing the P. pastoris $\mathrm{Mut}^{\mathrm{S}}$ strain expressing the enzyme horseradish peroxidase. Additionally, the authors express their gratitude to D. V. Rial (Consejo Nacional de Investigaciones Científicas y Técnicas CONICET, Argentina), who supported the experimental work in the lab.

\section{Authors' contributions}

$C D$ designed and performed the experiments and analyzed data. OS performed some experiments. $\mathrm{CD}$ and OS wrote the paper, $\mathrm{CH}$ conceived the study and supervised research. All authors read and approved the final manuscript.

\section{Competing interests}

The authors declare that they have no competing interests.

Received: 21 December 2010 Accepted: 3 March 2011 Published: 3 March 2011

\section{References}

1. Potgieter TI, Kersey SD, Mallem MR, Nylen AC, d'Anjou M: Antibody expression kinetics in glycoengineered Pichia pastoris. Biotechnology and Bioengineering 2010, 106:918-927.

2. Trinh $L B$, Phue JN, Shiloach J: Effect of methanol feeding strategies on production and yield of recombinant mouse endostatin from Pichia pastoris. Biotechnology and Bioengineering 2003, 82:438-444.

3. Kobayashi K, Kuwae S, Ohya T, Ohda T, Ohyama M, Tomomitsu K: High level secretion of recombinant human serum albumin by fed-batch fermentation of the methylotrophic yeast, Pichia pastoris, based on optimal methanol feeding strategy. Journal of Bioscience and Bioengineering 2000, 90:280-288.

4. Jacobs P, Inan M, Festjens N, Haustraete J, Van Hecke A, Meagher M, Contreras R, Callewaert N: Fed-batch fermentation of GM-CSF-producing glycoengineered Pichia pastoris under controlled specific growth rate. Microbial Cell Factories 2010, 9:93.

5. Jahic M, Rotticci-Mulder JC, Martinelle M, Hult K, Enfors SO: Modeling of growth and energy metabolism of Pichia pastoris producing a fusion protein. Bioprocess and Biosystems Engineering 2002, 24:385-393.

6. Zhang W, Sinha J, Smith LA, Inan M, Meagher MM: Maximization of Production of Secreted Recombinant Proteins in Pichia pastoris FedBatch Fermentation. Biotechnology Progress 2005, 21:386-393.

7. Sinha J, Plantz BA, Zhang W, Gouthro M, Schlegel V, Liu C-P, Meagher MM: Improved production of recombinant ovine interferon-t by Mut+ strain of Pichia pastoris using an optimized methanol feed profile. Biotechnology Progress 2003, 19:794-802.

8. Plantz BA, Sinha J, Villarete L, Nickerson KW, Schlegel VL: Pichia pastoris fermentation optimization: energy state and testing a growth-associated model. Applied Microbiology and Biotechnology 2006, 72:297-305.

9. Ohya T, Ohyama M, Kobayashi K: Optimization of human serum albumin production in methylotrophic yeast Pichia pastoris by repeated fedbatch fermentation. Biotechnology and Bioengineering 2005, 90:876-887.

10. Khatri NK, Hoffmann F: Oxygen-limited control of methanol uptake for improved production of a single-chain antibody fragment with recombinant Pichia pastoris. Applied Microbiology and Biotechnology 2006, 72:492-498.

11. Khatri NK, Hoffmann F: Impact of methanol concentration on secreted protein production in oxygen-limited cultures of recombinant Pichia pastoris. Biotechnology and Bioengineering 2006, 93:871-879.

12. Cunha AE, Clemente JJ, Gomes R, Pinto F, Thomaz M, Miranda S, Pinto R, Moosmayer D, Donner P, Carrondo MJT: Methanol induction optimization for scFv antibody fragment production in Pichia pastoris. Biotechnology and bioengineering 2004, 86:458-467.

13. d'Anjou MC, Daugulis AJ: A rational approach to improving productivity in recombinant Pichia pastoris fermentation. Biotechnology and bioengineering 2001, 72:1-11.

14. Ren H, Yuan J: Model-based specific growth rate control for Pichia pastoris to improve recombinant protein production. Journal of Chemical Technology and Biotechnology 2005, 80:1268-1272.

15. Ren HT, Yuan JQ, Bellgardt KH: Macrokinetic model for methylotrophic Pichia pastoris based on stoichiometric balance. Journal of Biotechnology 2003, 106:53-68.

16. Welinder KG: Amino acid sequence studies of horseradish peroxidase. 4. Amino and carboxyl termini, cyanogen bromide and tryptic fragments, the complete sequence, and some structural characteristics of horseradish peroxidase C. European Journal of Biochemistry 1979, 96:483-502.

17. Gajhede M: Horseradish peroxidase. Handbook of Metalloproteins 2001, 1:195-210

18. Rodriguez-Lopez JN, Lowe DJ, Hernandez-Ruiz J, Hiner ANP, GarciaCanovas F, Thorneley RNF: Mechanism of reaction of hydrogen peroxide with horseradish peroxidase: Identification of intermediates in the catalytic cycle. Journal of the American Chemical Society 2001, 123:11838-11847.

19. Veitch NC: Horseradish peroxidase: a modern view of a classic enzyme. Phytochemistry (Elsevier) 2004, 65:249-259.

20. Lai Y-C, Lin S-C: Application of immobilized horseradish peroxidase for the removal of $\mathrm{p}$-chlorophenol from aqueous solution. Process Biochemistry (Oxford, United Kingdom) 2004, 40:1167-1174.

21. Dalal S, Gupta MN: Treatment of phenolic wastewater by horseradish peroxidase immobilized by bioaffinity layering. Chemosphere 2007, 67:741-747.

22. Azevedo AM, Martins VC, Prazeres DMF, Vojinovic V, Cabral JMS, Fonseca LP: Horseradish peroxidase: a valuable tool in biotechnology. Biotechnology Annual Review 2003, 9:199-247.

23. Hamid M, Khalil ur R: Potential applications of peroxidases. Food Chemistry 2009, 115:1177-1186

24. Cregg JM, Editor: Pichia Protocols, Second Edition. [In: Methods Mol. Biol. (Totowa, NJ, U. S.)], 2007; 389] 2007.

25. Bradford MM: A rapid and sensitive method for the quantitation of microgram quantities of protein utilizing the principle of protein-dye binding. Analytical Biochemistry 1976, 72:248-254.

26. Laemmli UK: Cleavage of structural proteins during the assembly of the head of bacteriophage T4. Nature (London, United Kingdom) 1970, 227:680-685.

27. Herwig C, von Stockar U: A small metabolic flux model to identify transient metabolic regulations in Saccharomyces cerevisiae. Bioprocess and Biosystems Engineering 2002, 24:395-403.

28. Diderich JA, Schepper M, van Hoek P, Luttik MA, van Dijken JP, Pronk JT, Klaassen P, Boelens HF, de Mattos MJ, van Dam K, Kruckeberg AL: Glucose uptake kinetics and transcription of HXT genes in chemostat cultures of Saccharomyces cerevisiae. The Journal of biological chemistry 1999, 274:15350-15359.

29. Rizzi M, Theobald U, Querfurth E, Rohrhirsch T, Baltes M, Reuss M: In vivo investigations of glucose transport in Saccharomyces cerevisiae. Biotechnology and Bioengineering 1996, 49:316-327.

30. Kupcsulik B, Sevella B: Effects of methanol concentration on the recombinant Pichia pastoris MutS fermentation. Periodica Polytechnica, Chemical Engineering 2004, 48:73-87.

31. Cregg JM: Expression in the methylotrophic yeast Pichia pastoris. Gene Expression Systems 1999, 157-191.

32. Morawski B, Lin ZL, Cirino PC, Joo H, Bandara G, Arnold FH: Functional expression of horseradish peroxidase in Saccharomyces cerevisiae and Pichia pastoris. Protein Engineering 2000, 13:377-384.

doi:10.1186/1475-2859-10-14

Cite this article as: Dietzsch et al:: A dynamic method based on the specific substrate uptake rate to set up a feeding strategy for Pichia pastoris. Microbial Cell Factories 2011 10:14. 